\title{
Editorial
}

\section{Society for Endocrinology endocrine emergency guidance}

\author{
Marie Freel
}

Queen Elizabeth University Hospital, Glasgow, UK

\author{
Correspondence \\ should be addressed \\ to M Freel \\ Email \\ Marie.Freel@glasgow.ac.uk
}

Endocrine emergencies are potentially life-threatening clinical problems and are compounded by a lack of recognition leading to delays in therapy. Every endocrinologist is aware of patients attending their outpatient clinic, with tales of suboptimal care in a nonendocrine clinical environment because of a failure to understand their chronic condition and its possible complications. This is particularly relevant in adrenal insufficiency and has led to potentially avoidable excess morbidity and mortality.

To address this issue, the Clinical Committee of the Society for Endocrinology have launched a new initiative to introduce succinct and straightforward clinical guidance documents for use by the nonendocrinologist within an emergency setting. Five Emergency Guidance documents have been developed, often in conjunction with more comprehensive European, American or National guidelines. For the first time, all five are published together in this issue of Endocrine Connections.

Each guidance document covers the most common endocrine-themed medical emergencies:

- Adrenal insufficiency (1): this is often under-recognised and, in particular, there is a lack of understanding of 'sick day rules' amongst non-endocrine health professionals. This document clearly outlines key points in the recognition and management of a new presentation of adrenal insufficiency as well as clarifying how to alter glucocorticoid therapy in the event of intercurrent illness of medical procedures. The lead author of this guideline is Professor Weibke Arlt who was also an author on the Endocrine Society Clinical Practice Guideline and the diagnosis and treatment of primary adrenal insufficiency published in 2016 (2).
- Severe symptomatic hyponatraemia (3): this has been principally authored by Professor Stephen Ball who was also an author of the Clinical Practice guideline on hyponatraemia developed by the European Society for Endocrinology in 2014 (4). The particular strength of this guidance is that it emphasises the importance of assessing the severity of acute hyponatraemia and treating accordingly in the first instance. Evaluation of volume status and confirming the exact cause of hyponatraemia, whilst important, are often done poorly by non-specialist clinicians and delay the appropriate treatment of this common and potentially life-threatening condition.

- Acute hypocalcaemia (5) and hypercalcaemia (6): disorders of calcium regulation are the second most common electrolyte disorder requiring endocrine input. In these documents, Professor Jeremy Turner, Dr Jennifer Walsh and colleagues provide a concise summary of the key causes of hypocalcaemia and hypercalcaemia and their immediate management based upon biochemical severity and underlying cause: in the case of hypercalcaemia, the first step is rehydration with normal saline, and intravenous zoledronic acid is now the bisphosphonate of choice.

- Pituitary apoplexy (7): in this condition, recognition and prompt treatment with intravenous hydrocortisone may be life-saving and prevent long-term visual complications. In this guidance, Dr Stephanie Baldeweg and colleagues emphasise that this condition must be considered in patients with acute severe headache, visual defects and/or impairment of consciousness. Authors of this Emergency Guidance were also authors on the Society for Endocrinology's UK Guidelines for the management of pituitary apoplexy, published in 2011 and reviewed with no necessary changes in 2014 (8).

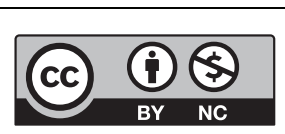

This work is licensed under a Creative Commons Attribution-NonCommercial 4.0 International License. 
Each guidance document has been principally written by authors with extensive experience and expertise in the relevant condition with consideration of the most up to date evidence available and has been peer-reviewed by the Society for Endocrinology Clinical Committee.

The Society wishes to distribute these important documents as widely as possible to a non-endocrine audience, most notably Emergency Departments and acute general medical and surgical wards. Publication of all documents in Endocrine Connections and subsequent availability on the Society for Endocrinology website will allow endocrinologists to provide a single point of reference to non-specialist colleagues to guide the management of these extremely common and important conditions.

\section{Declaration of interest}

The author declares that there is no conflict of interest that could be perceived as prejudicing the impartiality of this editorial.

\section{Funding}

This work did not receive any specific grant from any funding agency in the public, commercial, or not-for-profit sector.

\section{References}

1 Arlt W \& The Society for Endocrinology Clinical Committee. SOCIETY FOR ENDOCRINOLOGY ENDOCRINE EMERGENCY GUIDANCE: Emergency management of acute adrenal insufficiency (adrenal crisis) in adult patients. Endocrine Connections 5 G1-G3. (doi:10.1530/EC-16-0054)

2 Bornstein AR, Allolio B, Arlt W, Barthel A, Don-Wauchope A, Hammer GD, Husebye ES, Merke DP, Hassan Murad M, Stratakis CA, et al. Diagnosis and treatment of primary adrenal insufficiency: an Endocrine Society Clinical Practice Guideline. Journal of Clinical Endocrinology and Metabolism 2016101 364-389. (doi:10.1210/ jc.2015-1710)

3 Ball S, Barth J, Levy M \& The Society for Endocrinology Clinical Committee. SOCIETY FOR ENDOCRINOLOGY ENDOCRINE EMERGENCY GUIDANCE: Emergency management of severe symptomatic hyponatraemia in adult patients. Endocrine Connections 5 G4-G6. (doi:10.1530/EC-16-0058)

4 Spasovski G, Vanholder R, Allolio B, Annane D, Ball S, Bichet D, Decaux G, Fenske W, Hoorn E, Ichai C, et al. Clinical practice guideline on the diagnosis and treatment of hyponatraemia. European Journal of Endocrinology 2014170 G1-G47. (doi:10.1530/ EJE-13-1020)

5 Turner J, Gittoes N, Selby P \& The Society for Endocrinology Clinical Committee. SOCIETY FOR ENDOCRINOLOGY ENDOCRINE EMERGENCY GUIDANCE: Emergency management of acute hypocalcaemia in adult patients. Endocrine Connections 5 G7-G8. (doi:10.1530/EC-16-0056)

6 Walsh J, Gittoes N, Selby P \& The Society for Endocrinology Clinical Committee. SOCIETY FOR ENDOCRINOLOGY ENDOCRINE EMERGENCY GUIDANCE: Emergency management of acute hypercalcaemia in adult patients. Endocrine Connections 5 G9-G11. (doi:10.1530/EC-16-0055)

7 Baldeweg SE, Vanderpump M, Drake W, Reddy N, Markey A, Plant GT, Powell M, Sinha S, Wass J \& The Society for Endocrinology Clinical Committee. SOCIETY FOR ENDOCRINOLOGY ENDOCRINE EMERGENCY GUIDANCE: Emergency management of pituitary apoplexy in adult patients. Endocrine Connections 5 G12-G15. (doi:10.1530/EC-16-0057)

8 Rajasekaran S, Vanderpump M, Baldeweg S, Drake W, Reddy N, Lanyon M, Markey A, Plant G, Powell M, Sinha S, et al. UK guidelines for the management of pituitary apoplexy. Clinical Endocrinology 2011 74 9-20. (doi:10.1111/j.1365-2265.2010.03913.x)

Received in final form 26 August 2016

Accepted 26 August 2016 http://www.endocrineconnections.org DOI: 10.1530/EC-16-0068
C 2016 The author Published by Bioscientifica Ltd

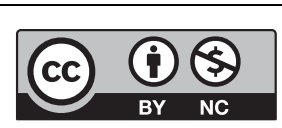

This work is licensed under a Creative Commons Attribution-NonCommercial 4.0 International License. 